\title{
Sensitivity to Climate and Weather Changes in Euthymic Bipolar Subjects: Association With Suicide Attempts
}

\author{
Marco Di Nicola ${ }^{1,2 *}$, Marianna Mazza ${ }^{1,2}$, Isabella Panaccione ${ }^{3}$, Lorenzo Moccia ${ }^{1,2}$, \\ Giulia Giuseppin ${ }^{2}$, Giuseppe Marano ${ }^{2}$, Paolo Grandinetti ${ }^{4}$, Giovanni Camardese ${ }^{1,2}$, \\ Domenico De Berardis ${ }^{5}$, Maurizio Pompili ${ }^{6}$ and Luigi Janiri ${ }^{1,2 *}$
}

OPEN ACCESS

Edited by:

Donatella Marazziti,

University of Pisa, Italy

Reviewed by:

Federico Mucci,

University of Pisa, Italy Carlo Antonio Bertelloni,

University of Pisa, Italy

Kevin Swierkosz-Lenart, Lausanne University Hospital (CHUV).

Switzerland

*Correspondence: Marco Di Nicola

marcodinicola.md@gmail.com

Luigi Janiri

luigi.janiri@unicatt.it

Specialty section: This article was submitted to

Public Mental Health,

a section of the journal

Frontiers in Psychiatry

Received: 19 August 2019 Accepted: 05 February 2020

Published: 05 March 2020

Citation:

Di Nicola M, Mazza M, Panaccione I, Moccia L, Giuseppin G, Marano G,

Grandinetti P, Camardese G,

De Berardis D, Pompili $M$ and Janiri $L$ (2020) Sensitivity to Climate and Weather Changes in Euthymic Bipolar Subjects: Association With Suicide Attempts.

Front. Psychiatry 11:95. doi: 10.3389/fpsyt.2020.00095
1 Department of Psychiatry, Fondazione Policlinico Universitario "A. Gemelli" IRCCS, Rome, Italy, ${ }^{2}$ Institute of Psychiatry, Università Cattolica del Sacro Cuore, Rome, Italy, ${ }^{3}$ Department of Mental Health, ASL Roma 1, Rome, Italy, ${ }^{4}$ Department of Mental Health, AUSL Modena, Modena, Italy, ${ }^{5}$ Department of Mental Health, Psychiatric Service of Diagnosis and Treatment, Hospital "G. Mazzini", Teramo, Italy, ${ }^{6}$ Suicide Prevention Centre, Department of Neurosciences, Mental Health and Sensory Organs, Sant'Andrea Hospital, Sapienza University of Rome, Rome, Italy

Background: Climate and weather are known to affect multiple areas of human life, including mental health. In bipolar disorder (BD), seasonality represents an environmental trigger for mood switches, and climatic variables may contribute to recurrences. Several studies reported seasonal and climatic-related variations in the rate of suicide attempts. Suicide risk is relevant in BD, with approximately $25 \%$ of patients attempting suicide. Therefore, this study aimed to assess sensitivity to weather and climatic variations in BD subjects and its relationship with lifetime suicide attempts.

Methods: Three hundred fifty-two euthymic BD and 352 healthy control subjects, homogeneous with respect to socio-demographic characteristics, were enrolled. All participants were administered the METEO-Questionnaire (METEO-Q) to evaluate susceptibility to weather and climatic changes. We also investigated the potential relationship between sensitivity to climate and weather and lifetime suicide attempts in BD patients.

Results: METEO-Q scores and the number of subjects reaching the cut-off for meteorosensitivity/meteoropathy were significantly higher in $\mathrm{BD}$ patients. Within the clinical group, BD subjects with lifetime suicide attempts obtained higher METEO-Q scores, with no differences between BD-I and BD-II. The number of suicide attempts directly correlated with METEO-Q scores. The presence of suicide attempts was associated with the physical and psychological symptoms related to weather variations.

Discussion: Our findings support the relevance of sensitivity to weather and climate variations in a large sample of BD subjects and point out the association of this feature with lifetime suicide attempts.

Keywords: weather, climate, meteoropathy, bipolar disorder, suicide, personalized medicine 


\section{INTRODUCTION}

The strict relationship between health and environment is well known, and there is increasing evidence that climate and weather affect multiple areas of human life, including mental health (1). For example, "pleasant weather" (e.g., elevated temperature or barometric pressure) seems to be related to higher mood levels, better memory, and broadened cognitive style (2), whereas high levels of humidity have been associated with impaired concentration and increased sleepiness (3). Though generally experienced only to a mild degree, some individuals display extreme sensitivity to weather and climatic changes $(4,5)$.

Psychiatric patients have been described to be particularly vulnerable to climate and weather changes in terms of clinical severity, admission rates, duration of hospitalization, recurrences, and outcome (6-9). Accordingly, a recent study found correlations between different weather conditions and the number of patients accessing the emergency room for psychiatric symptoms (10).

Among psychiatric diseases, bipolar disorder (BD) is the fifth highest as to self-reported disability, represents a significant public health problem, and is saddled with a markedly high mortality rate from suicide $(11,12)$.

There is a consensus on considering the changing of the seasons as one important environmental trigger for mood switches in $\mathrm{BD}$, and emerging evidence suggests that climatic variables may contribute to recurrences $(13,14)$. Some studies reported a relationship between hospitalizations for mania and hours of sunshine, or temperature (15-17). Christensen and colleagues (18) found that several meteorological factors, including changes in minimum and maximum temperature, rainfall, atmospheric pressure, and cloudiness, might contribute to triggering new episodes in bipolar patients. Additional findings entailing climate variables include the observed association between hospital admissions for bipolar depression and temperature (19), as well as the prevalence of depressive episodes in relation to latitude (20), although other researchers reported different results (21). Interestingly, a recent study found a significant inverse association between the maximum monthly increase in solar insolation and the age of onset of type I BD (22).

Several evidences described seasonal and climatic-related variations in suicidality, with different patterns in men and women (23-28). Of note, climate and weather seem to independently influence suicidal behavior, both in psychiatric patients and in the general population. Fountoulakis et al. (29) described a correlation between the number of suicides and environmental temperature in different European countries, and climate changes appeared to influence suicidality even more than socio-economic factors. These observations have been further supported by a recent study that found a significant impact of temperature fluctuations on suicide rates in a large sample of subjects across the USA and Mexico (30). Seasonal effects have been reported to play a role in the likelihood of suicidal behaviors in affective disorder patients $(31,32)$. In manic BD subjects, higher suicide risk has been associated to rapidly increasing temperatures (33).

Following these considerations, we hypothesized that bipolar subjects would show a higher rate of sensitivity to climatic changes and that this feature could be related to suicide risk. Our group devised and validated a self-administered instrument, the METEO-Questionnaire (METEO-Q), to detect sensitivity to climate and weather changes in the general population and to assess their impact on symptom variations in psychiatric patients (34).

The aims of the study were: (i) to investigate sensitivity to weather and climate variation in euthymic bipolar subjects as compared to homogeneous healthy controls, using the METEOQ; (ii) to evaluate the relationship of susceptibility to weather/ climate changes with lifetime suicide attempts (SAs) in BD.

\section{METHODS}

\section{Participants}

Participants were recruited among outpatients referring to the Day-Hospital of Psychiatry at the Fondazione Policlinico Universitario “A. Gemelli” IRCCS, Università Cattolica del Sacro Cuore, Rome, between January 2016 and May 2019. Inclusion criteria were: age 18 to 70; DSM-5 diagnosis of BD (type I and II); euthymia for at least three months; fluency in both spoken and written Italian. Exclusion criteria were: documented mental retardation or IQ $<70$; alcohol/substance use disorders in the last three months; comorbidity with neurological or endocrine diseases. Psychiatric comorbidities were assessed by the Structured Clinical Interview for DSM-IV Axis I and II disorders (SCID-I/P; SCID-II) $(35,36)$. All included patients had been under stable pharmacological treatment for at least six months. The clinical sample finally consisted of $352 \mathrm{BDs}$ (149 type I; 203 type II) subjects.

Healthy controls (HC) were recruited from community volunteers through advertisements. HC subjects were free of any psychiatric diagnoses as determined by the SCID-I, Nonpatient edition (SCID-I/NP) and the SCID-II $(35,37)$. Exclusion criteria were: history of brain trauma; lifetime neurological and endocrine illnesses; current psychopharmacological or psychotherapeutic treatment. None of them reported lifetime suicidal attempts. Three hundred fifty-two HC subjects were ultimately enrolled in the study.

Anonymity was guaranteed to all participants. The study protocol fully complied with the guidelines of the local Ethics Committee and was approved by the Institutional Review Boards in agreement with local requirements. It was conducted in accordance with Good Clinical Practice guidelines and the Declaration of Helsinki (1964) and subsequent revisions. All subjects enrolled gave their written informed consent before their inclusion in the study and participated without receiving any form of payment.

\section{Procedure and Assessment}

A semistructured interview was employed to obtain demographic information, as well as medical/psychiatric history. SAs were assessed with a semistructured questionnaire including two questions: "Have you ever attempted suicide?"; "If yes, how many times have you attempted suicide?" SA was defined as "a selfinflicted, potentially injurious behavior with a nonfatal outcome for 
which there was evidence (either explicit or implicit) of intent to die" (38).

The assessment of mood state (euthymia for at least three months) was based on clinical and psychometric evaluations (i.e., Hamilton Depression Rating Scale < 8 (39); Young Mania Rating Scale $<6$ (40).

All participants were administered the METEO-Questionnaire (METEO-Q) to evaluate susceptibility to weather and climatic changes. The device consists of 11 items and a structured checklist aimed at identifying the physical and psychological symptoms related to climate variations. Items and checklist symptoms are rated on a five-point Likert scale ranging from 0 (absent) to 4 (severe). The questionnaire also differentiates between "meteorosensitivity" and "meteoropathy": subjects biologically susceptible to feel the effects of atmospherical events on mind and body are defined "meteorosensitive," whereas individuals who develop a specific illness or a worsening of the existing diseases as a consequence of climatic changes are called "meteoropathic." Different threshold values for detecting meteorosensitivity and meteoropathy in men and women were established (men: METEO-Q total scores $>6$ for meteosensitivity, $>9$ for meteoropathy; women: METEO-Q total scores $>8$ for meteosensitivity, > 11 for meteoropathy) (34). Raters (MDN and $\mathrm{MM}$ ) were specifically trained and showed good inter-rater reliability on all instruments $(\mathrm{kN}=0.80)$.

Upon evaluation, patients underwent a naturalistic maintenance treatment, with established mood stabilizers (lithium, valproate, carbamazepine) and atypical antipsychotics (olanzapine, quetiapine, aripiprazole, asenapine).

\section{Statistical Analysis}

Statistical analyses were performed using the software IBM-SPSS Statistics, Version 24.0. Dichotomous data were described as numbers and percentages and compared using either the Chisquare test or Fisher's exact test; continuous data were reported as mean $(\mathrm{M}) \pm$ standard deviation $(\mathrm{SD})$ and compared by Independent-Samples T-test or by non-parametric MannWhitney $U$ test if not normally distributed. Bravais-Pearson or non-parametric Spearman's rank correlation coefficients were reported as measures of association between continuous variables. Factors significantly associated with suicidal attempts in bivariate analyses were subjected to a multivariate logistic regression with SAs as dependent outcome measures. We examined all variables for multicollinearity. The HosmerLemeshow goodness-of-fit statistic was used to check the fit of the model. Findings were reported as odds ratios (OR) and $\mathrm{p}$ values. All tests were two-tailed, with statistical significance set at $\mathrm{p}<.05$.

\section{RESULTS}

\section{Demographic and Clinical Features in Bipolar vs. HC Subjects}

All participants were Caucasians and homogeneous for age, gender, level of education, but not for marital status and employment condition (Table 1).
TABLE 1 | Demographic and clinical data of euthymic bipolar disorder and healthy control subjects.

\begin{tabular}{|c|c|c|c|c|}
\hline & $\begin{array}{c}\text { Bipolar Disorders } \\
\text { subjects }\end{array}$ & $\begin{array}{l}\text { Healthy } \\
\text { Controls }\end{array}$ & $t / Z / \chi^{2}$ & $\mathbf{p}$ \\
\hline $\mathrm{N}$ & 352 & 352 & & \\
\hline Gender (male) (n, \%) & $130(37)$ & $141(40)$ & .817 & .366 \\
\hline Age $(\mathrm{M} \pm \mathrm{SD})$ & $48.9 \pm 11.4$ & $48.8 \pm 11.4$ & -1.67 & .867 \\
\hline $\begin{array}{l}\text { Educational level (years, } \\
M \pm S D \text { ) }\end{array}$ & $13.1 \pm 3.2$ & $13.3 \pm 2.6$ & 1.054 & .292 \\
\hline Marital status (n, \%) & & & 17.08 & .001 \\
\hline Single & $118(33.6)$ & $114(32.5)$ & & \\
\hline Married & $161(45.6)$ & $203(57.8)$ & & \\
\hline Separated/divorced & $58(16.5)$ & $27(7.6)$ & & \\
\hline Widowed & $15(4.3)$ & $8(2.1)$ & & \\
\hline $\begin{array}{l}\text { Employment condition } \\
(\mathrm{n}, \%)\end{array}$ & & & 42.55 & $<.001$ \\
\hline Student & $13(3.7)$ & $8(2.3)$ & & \\
\hline Occasionally employed & $41(11.6)$ & $66(18.8)$ & & \\
\hline Regular job & $168(47.7)$ & $217(61.5)$ & & \\
\hline Retired & $41(11.6)$ & $34(9.7)$ & & \\
\hline Unemployed & 89 (25.3) & $27(7.8)$ & & \\
\hline \multicolumn{5}{|l|}{ Clinical data } \\
\hline Current smoking (n, \%) & 177 (50.3) & $149(42.4)$ & 4.081 & .079 \\
\hline $\begin{array}{l}\text { Onset of illness (age, M } \\
\pm \text { SD) }\end{array}$ & $28.7 \pm 11.9$ & - & & \\
\hline $\begin{array}{l}\text { Duration of illness } \\
\text { (years, } M \pm S D)\end{array}$ & $19.2 \pm 12.1$ & - & & \\
\hline $\begin{array}{l}N^{\circ} \text { of affective episodes } \\
(M \pm S D)\end{array}$ & $5.7 \pm 5.1$ & - & & \\
\hline $\begin{array}{l}N^{\circ} \text { of hospitalizations (M } \\
\pm \mathrm{SD} \text { ) }\end{array}$ & $2.1 \pm 3.4$ & - & & \\
\hline $\begin{array}{l}\text { Psychiatric comorbidity } \\
(\mathrm{n}, \%)\end{array}$ & $88(25)$ & - & & \\
\hline Suicide attempts (n, \%) & $82(23.3)$ & - & & \\
\hline $\mathrm{N}^{\circ}$ of suicides $(\mathrm{M} \pm \mathrm{SD})$ & $1.54 \pm .95$ & - & & \\
\hline \multicolumn{5}{|l|}{$\begin{array}{l}\text { Bipolar Disorder } \\
\text { diagnosis (n, \%) }\end{array}$} \\
\hline BD type I & $149(42.3)$ & - & & \\
\hline BD type II & $203(57.7)$ & - & & \\
\hline \multicolumn{5}{|l|}{$\begin{array}{l}\text { Pharmacological } \\
\text { treatment (n, \%) }\end{array}$} \\
\hline Lithium & $162(46)$ & & & \\
\hline $\begin{array}{l}\text { Antiepileptics mood } \\
\text { stabilizers }\end{array}$ & $208(59)$ & & & \\
\hline \multicolumn{5}{|l|}{ Psychometric } \\
\hline \multicolumn{5}{|l|}{ assessment $(\mathrm{M} \pm \mathrm{SD})$} \\
\hline HDRS & $2.97 \pm 1.3$ & $2.78 \pm 1.64$ & -1.213 & .226 \\
\hline YMRS & $1.21 \pm .78$ & $1.06 \pm 1.42$ & -1.373 & .170 \\
\hline METEO-Q Total & $21.6 \pm 11.8$ & $13.4 \pm 8.2$ & -9.666 & $<.001$ \\
\hline METEO-Q Checklist & $30 \pm 18.6$ & $16 \pm 12.8$ & -10.475 & $<.001$ \\
\hline
\end{tabular}

Significant results are reported in bold characters.

BD, Bipolar Disorder; $\chi 2$, Chi-square test; HDRS, Hamilton Depression Rating Scale; $M$, mean; $N$, number of cases; $p$, statistical significance; $S D$, standard deviation; t, Independent Samples t-test; YMRS, Young Mania Rating Scale; Z, Mann-Whitney U test.

In $\mathrm{BD}$ subjects comorbid disorders were anxiety disorders (generalized anxiety disorder: $\mathrm{n}=18,5.1 \%$; panic disorder: $\mathrm{n}=14$, $3.9 \%$; social anxiety disorder: $n=5,1.4 \%$ ), eating disorders (bulimia nervosa: $n=6,1.7 \%$; anorexia nervosa: $n=3,0.8 \%$ ), obsessive compulsive disorder $(n=10,2.8 \%)$; personality disorders (borderline: $\mathrm{n}=13,3.7 \%$; obsessive-compulsive: $\mathrm{n}=8$, $2.3 \%$; histrionic: $\mathrm{n}=5,1.4 \%$; avoidant: $\mathrm{n}=4,1.1 \%$; narcissistic: $\mathrm{n}=2,0.6 \%)$. 
METEO-Q Total and Checklist scores were higher in BD than in HC subjects (Table 1), with no differences between BD I and II types.

The rate of individuals reaching the cut-off for meteorosensitivity/meteoropathy was higher in bipolar subjects than in HC (meteorosensitivity: $5.4 \%$ vs. $16.3 \%$; meteoropathy: $82.7 \%$ vs. $\left.59.4 \% ; \chi^{2}=39.42 ; \mathrm{p}<.001\right)$, with no differences between BD I and BD II patients.

Women reported higher METEO-Q Total and Checklist scores both in the clinical sample (METEO-Q Total: $22.8 \pm$ 11.4 vs. $19.3 \pm 12.1 ; \mathrm{t}=-2.517, \mathrm{p}=.012$. METEO-Q Checklist: $31.5 \pm 19.1$ vs. $27 \pm 17.3 ; \mathrm{t}=-2.013, \mathrm{p}=.045)$ and in controls (METEO-Q Total: $15.2 \pm 8.3$ vs. $10.2 \pm 6.8$; $\mathrm{t}=-5.282, \mathrm{p}<.001$. METEO-Q Checklist: $18.2 \pm 13$ vs. $12.4 \pm 11.7$; $\mathrm{t}=-3.774, \mathrm{p}<$ $.001)$. Only in the HC group, a significant gender difference in reaching the cut-off of meteorosensitivity/meteoropathy was found, with higher rates in females (meteorosensitivity: $17.4 \%$ vs. $14.3 \%$; meteoropathy: $63.5 \%$ vs. $\left.52.4 \% ; \chi^{2}=7.256 ; \mathrm{p}=.027\right)$.

There were no correlations between METEO-Q scores (Total, Checklist) and HDRS and YMRS scores in both clinical and control groups.

\section{Sensitivity to Climate/Weather Changes and SAs in Bipolar Subjects}

To fit our aims, we subdivided the clinical sample into bipolar subjects with $(n=82)$ and without $(n=270)$ a lifetime history of one or more SAs. The two groups did not significantly differ for socio-demographic and clinical features, except for age of onset (BD+SA vs. BD: $25.3 \pm 10.3$ vs. $30.9 \pm 12.3$; $\mathrm{t}=3.343, \mathrm{p}=.001)$ and occupation typology, with higher rates of students and lower rates of regularly employed subjects in the $\mathrm{BD}+\mathrm{SA}$ group $\left(\chi^{2}=\right.$ 12.699, $\mathrm{p}=.013$ ).

BD patients with lifetime SAs obtained significantly higher METEO-Q scores (METEO-Q Total: $24.8 \pm 13$ vs. $19.6 \pm 10.3$; $\mathrm{t}=-3.142, \mathrm{p}=.002$. METEO-Q Checklist: $37.6 \pm 20.3$ vs. $26.6 \pm$ $16.2 ; \mathrm{t}=-4.18, \mathrm{p}<.001$ ), with no differences between BD I and BD II subjects. The number of SAs directly correlated with METEOQ Total $(\rho=.217, p=.002)$ and Checklist $(\rho=.334, p<.001)$ scores. No differences in the number of subjects reaching the cut-off scores for meteorosensitivity/meteoropathy were found in the two groups.

Finally, multivariate logistic regression analysis indicated that lifetime SAs were associated with the physical and psychological symptoms related to climate variations (METEO-Q Checklist: $\mathrm{OR}=1.03, \mathrm{p}=.01$ ).

\section{DISCUSSION}

$\mathrm{BD}$ is characterized by a high degree of psychopathological burden, with significant rates of relapses and recurrences. Many different factors, both individual and environment-related, have been recognized as triggers for the development of new episodes and the worsening of residual inter-episode symptoms. Among these factors, seasonality (41), the dysregulation of circadian rhythms
(42), as well as abnormalities in the biological response to sunlight $(43,44)$ and moon cycle $(45)$, have been demonstrated to play a significant role. Therefore, climate and weather sensitivity would be expected to be related to the course of the illness as well.

In this study, we found a higher susceptibility to weather and climatic changes in BD patients compared to homogeneous $\mathrm{HC}$. Since patients were all euthymic and evaluated at different times of the year, results are likely not influenced by current mood state or specific seasonality, possibly representing an enduring trait (46).

The hypothesized neurobiological mechanisms influencing sensitivity to climate changes are complex and involve many factors, including different neurotransmission pathways, the immune and neuroendocrine systems, and the activity of genes regulating circadian rhythms $(14,47)$.

Recently, genetic variations in the circadian gene neuronal PAS domain protein 2 (NPAS2) have been proposed as a biomarker for a seasonal pattern in BD (41). Of note, both circadian rhythms and the response to sunlight and to climatic variations are regulated by the hypothalamus, whose role in the pathophysiology of $\mathrm{BD}$ has been discussed (48).

$\mathrm{BD}$ is associated with a high risk of SAs and deaths. It is estimated that the risk of suicide in BD patients is 20-30 times greater than in the general population (49). Epidemiological studies report that about $23 \%-26 \%$ of BD patients attempt suicide and that BD accounts for up to $14 \%$ of all deaths by suicide (50).

Intriguingly, in our clinical sample the sensitivity to weather changes was associated with the presence and number of lifetime SAs. This finding is relevant, since a history of a prior SA has a documented predictive role for completed suicide, and repeated attempts further increase the risk of death by suicide (51). There is evidence supporting the influence of seasonal changes on suicidal behavior that seems to be related to climatic variance and light exposure, possibly through an interaction with serotonergic and noradrenergic circuits $(29,47)$. Meteorological variables, such as temperature, atmospheric pressure, and sunlight, are linked to changes in the concentration of cerebral neurotransmitters and alterations in the serotonin turnover in the brain (47). A study by Makris et al. (52) found a correlation between sunshine and SAs in patients treated with serotonergic medications (i.e., SSRI). Therefore, environmental, weather-related neurobiological alterations of the serotonergic system might mediate suicidal behavior in predisposed individuals (47). Of note, dysfunctions in the serotonergic and dopaminergic systems have been also shown to play a role in the pathophysiological mechanisms underlying emotion dysregulation, which, in turn, is strongly linked to mood recurrences, impulsive behaviors, and substance abuse, ultimately leading to an increased risk of suicide in BD patients (53-55). Similarly, meteorological factors, including low barometric pressure, high temperatures and precipitations, have been associated with decreased sleep quality and abnormal circadian patterns $(56,57)$, which, in turn, may represent a potential marker of SA in $\mathrm{BD}$ (58).

Seasonal and climatic factors might interact with each other, influencing the manifestation of psychiatric symptoms mostly 
affecting suicide completers (59). Balestrieri et al. (60) suggested that the assessment of lifetime rhythmicity and manichypomanic features may be clinically useful to identify potential suicide attempters in high-risk groups. In a recent study, Bauer et al. (61) found an association between latituderelated changes in solar insolation and increased SAs in patients with BD. Finally, the weather has a significant impact on social activities and interactions, especially in vulnerable populations. Interpersonal stress, low social connectedness, and poor social support have been recognized as major risk factors for suicide (62-64).

In our study, women displayed a greater tendency to climatic sensitivity than men both in the clinical and in the control group, a finding in line with earlier observations (65). The greater influence exerted by seasonality and climatic changes on women could be determined by the different action of bioclimatic factors on neurohormonal systems.

Increased sensitivity to climate and weather variables, especially among fragile populations such as psychiatric patients, represents an issue to be considered in the light of the severe climatic modifications currently taking place. In fact, global climate change is now regarded as one of the biggest crisis facing humanity, and the impact of its consequences on mental health, both in adults and children, has been recognized as a major concern among mental health specialists (66-72). Accordingly, in 2017 the American Psychiatry Association (APA) released a position statement that climate change "poses a threat to public health, including mental health", with people suffering from psychiatric disorders expected to be more dramatically impacted (73). This statement has been recently followed by an editorial of the European College of Neuropsychopharmacology (ECNP) President highlighting the need for more research on this field, and for further measures to mitigate the consequences of climate changes on mental health (74).

Increasing evidence indicates that climate change may affect mental health via multiple mechanisms, both direct and indirect, leading to outcomes ranging from psychological distress, fear, anxiety, or depression, to sleep disorders, substance use, and suicide $(67,70,75)$. In our sample the symptomatic load, both physical and psychological, related to climate and weather variations was associated with lifetime SAs. Currently, suicide is one of the leading causes of death worldwide, and suicide rates in the U.S. have risen dramatically over the last 15 years, especially in adolescents and young adults aged 15 to 34 (76). Burke et al. described that temperature rising could increase the suicide rate by $1.4 \%$ in the U.S. and by $2.3 \%$ in Mexico, leading to an estimated number of about 21.000 additional suicides by 2050 in these countries (30). Therefore, a better understanding of the

\section{REFERENCES}

1. McMichael AJ. Globalization, climate change, and human health. New Engl J Med (2013) 368:1335-43. doi: 10.1056/NEJMra1109341

2. Keller MC, Fredrickson BL, Ybarra O, Côté S, Johnson K, Mikels J, et al. A warm heart and a clear head. The contingent effects of weather on mood and cognition. Psychol Sci (2005) 16:724-31. doi: 10.1111/j.1467-9280.2005.01602.x multiple causes influencing suicidal behaviors is indeed a public health priority.

Our results must be considered in the light of some issues referred to the design of the study, such as: the absence of objective measures of climatic parameters (i.e., latitude, barometric pressure, temperature, brightness, and precipitation); the reliability of a self-administered questionnaire (the METEO-Q), that may be partially biased as compared with semistructured interviews; the cross-sectional nature of the study, that does not follow individuals over time and does not help determine cause and effect. Therefore, our results in this sample may not be generalizable for other groups of subjects.

Our findings support the relevance of sensitivity to weather and climatic variations as a clinical characteristic in a large sample of $\mathrm{BD}$ patients. The association between sensitivity to weather changes and SAs could be useful in the assessment of suicide risk in $\mathrm{BD}$ patients.

Further studies that replicate our findings and investigate clinical and research implications are certainly needed.

\section{DATA AVAILABILITY STATEMENT}

The datasets analyzed for this study are available from the corresponding authors on reasonable request.

\section{ETHICS STATEMENT}

The studies involving human participants were reviewed and approved by the Ethics Committee of the Fondazione Policlinico Universitario “A. Gemelli” IRCCS, Università Cattolica del Sacro Cuore, Rome, Italy. The patients/participants provided their written informed consent to participate in this study.

\section{AUTHOR CONTRIBUTIONS}

MN and LJ were primarily responsible for study design and contributed to data interpretation and article writing. MM, GC, and PG performed data collection and contributed to data interpretation. GG and GM were involved in data entry and database management. MN performed statistical analysis. $\mathrm{MN}$, $\mathrm{MM}, \mathrm{MP}$, and DDB were involved in data interpretation. IP, LM, and GG contributed to data interpretation and article writing. All authors personally revised and approved the final version of the manuscript.
3. Howarth E, Hoffman MS. A multidimensional approach to the relationship between mood and weather. Br J Psychol (1984) 75(Pt 1):15-23. doi: 10.1111/ j.2044-8295.1984.tb02785.x

4. Huibers MJ, de Graaf LE, Peeters FP, Arntz A. Does the weather make us sad? Meteorological determinants of mood and depression in the general population. Psychiatry Res (2010) 180:143-6. doi: 10.1016/j.psychres. 2009.09.016 
5. O'Hare C, O'Sullivan V, Flood S, Kenny RA. Seasonal and meteorological associations with depressive symptoms in older adults: A geo-epidemiological study. J Affect Disord (2016) 191:172-9. doi: 10.1016/j.jad.2015.11.029

6. Santiago PN, McLay RN, Hammer PS. Meteorologic factors in emergency evaluation, admission, and discharge. Psychiatr Serv (2005) 56:1625. doi: 10.1176/appi.ps.56.12.1625

7. Hansen A, Bi P, Nitschke M, Ryan P, Pisaniello D, Tucker G. The effect of heat waves on mental health in a temperate Australian city. Environ Health Perspect (2008) 116:1369-75. doi: 10.1289/ehp.11339

8. Cervellin G, Comelli I, Lippi G, Comelli D, Rastelli G. Ossola P, et al. The number of emergency department visits for psychiatric emergencies is strongly associated with mean temperature and humidity variations. Results of a nine year survey. Emerg Care J (2014) 10. doi: 10.4081/ecj.2014.2271

9. Majeed H, Lee J. The impact of climate change on youth depression and mental health. Lancet Planet Health (2017) 1:e94-5. doi: 10.1016/S2542-5196 (17)30045-1

10. Brandl EJ, Lett TA, Bakanidze G, Heinz A, Bermpohl F, Schouler-Ocak M. Weather conditions influence the number of psychiatric emergency room patients. Int J Biometeorol (2018) 62:843-50. doi: 10.1007/s00484-017-1485-z

11. Andrews G, Henderson S, Hall W. Prevalence, comorbidity, disability and service utilisation. Overview of the Australian National Mental Health Survey. Br J Psychiatry (2001) 178:145-53. doi: 10.1192/bjp.178.2.145

12. Osby U, Brandt L, Correia N, Ekbom A, Sparen P. Excess mortality in bipolar and unipolar disorder in Sweden. Arch Gen Psychiatry (2001) 58:844-50. doi: 10.1001/archpsyc.58.9.844

13. Geoffroy PA, Bellivier F, Scott J, Etain B. Seasonality and bipolar disorder: a systematic review, from admission rates to seasonality of symptoms. J Affect Disord (2014) 168:210-23. doi: 10.1016/j.jad.2014.07.002

14. Young JW, Dulcis D. Investigating the mechanism(s) underlying switching between states in bipolar disorder. Eur J Pharmacol (2015) 759:151-62. doi: 10.1016/j.ejphar.2015.03.019

15. Volpe FM, Del Porto JA. Seasonality of admissions for mania in a psychiatric hospital of Belo Horizonte, Brazil. J Affect Disord (2006) 94:243-8. doi: 10.1016/j.jad.2006.03.025

16. Lee HC, Tsai SY, Lin HC. Seasonal variations in bipolar disorder admissions and the association with climate: a population-based study. J Affect Disord (2007) 97:61-9. doi: 10.1016/j.jad.2006.06.026

17. Parker G, Hadzi-Pavlovic D, Bayes A, Graham R. Relationship between photoperiod and hospital admissions for mania in New South Wales, Australia. J Affect Disord (2018) 226:72-6. doi: 10.1016/j.jad.2017.09.014

18. Christensen EM, Larsen JK, Gjerris A, Peacock L, Jacobi M, Hassenbalch E. Climatic factors and bipolar affective disorder. Nord J Psychiatry (2008) 62:55-8. doi: 10.1080/08039480801970049

19. Shapira A, Shiloh R, Potchter O, Hermesh H, Popper M, Weizman A. Admission rates of bipolar depressed patients increase during spring/ summer and correlate with maximal environmental temperature. Bipolar Disord (2004) 6:90-3. doi: 10.1046/j.1399-5618.2003.00081.x

20. Friedman E, Gyulai L, Bhargava M, Landen M, Wisniewski S, Foris J, et al. Seasonal changes in clinical status in bipolar disorder: a prospective study in 1000 STEP-BD patients. Acta Psychiatr Scand (2006) 113:510-7. doi: 10.1111/ j.1600-0447.2005.00701.x

21. Bauer M, Glenn T, Grof P, Rasgon NL, Marsh W, Sagduyu K, et al. Relationship among latitude, climate, season and self-reported mood in bipolar disorder. $J$ Affect Disord (2009) 16:152-7. doi: 10.1016/j.jad.2008.11.013

22. Bauer M, Glenn T, Alda M, Aleksandrovich MA, Andreassen OA, Angelopoulos E, et al. Solar insolation in springtime influences age of onset of bipolar I disorder. Acta Psychiatr Scand (2017) 136:571-82. doi: 10.1111/ acps. 12772

23. Linkowski P, Martin F, De Maertelaer V. Effect of some climatic factors on violent and non-violent suicides in Belgium. J Affect Disord (1992) 25:161-6. doi: 10.1016/0165-0327(92)90001-M

24. Maes M, De Meyer F, Thompson P, Peeters D, Cosyns P. Synchronized annual rhythms in violent suicide rate, ambient temperature and the light-dark span. Acta Psychiatr Scand (1994) 90:391-6. doi: 10.1111/j.1600-0447.1994.tb01612.x

25. Deisenhammer EA, Kemmler G, Parson P. Association of meteorological factors with suicide. Acta Psychiatr Scand (2003) 108:455-9. doi: 10.1046/ j.0001-690X.2003.00219.x
26. Pompili M, Girardi P, Ruberto A, Tatarelli R. Seasonality and suicide. Psychiatry Res (2004) 128:301-2. doi: 10.1016/j.psychres.2004.06.001

27. Akkaya-Kalayci T, Vyssoki B, Winkler D, Willeit M, Kapusta ND, Dorffner G, et al. The effect of seasonal changes and climatic factors on suicide attempts of young people. BMC Psychiatry (2017) 17:365. doi: 10.1186/s12888017-1532-7

28. Santurtún M, Sanchez-Lorenzo A, Del Real Á, Zarrabeitia MT, Santurtún A. Association Between Suicide and Environmental Variables in the North of Spain: A 14-Year Analysis. Cult Med Psychiatry (2018) 42:647-53. doi: 10.1007/s11013-018-9578-7

29. Fountoulakis KN, Chatzikosta I, Pastiadis K, Zanis P, Kawohl W, Kerkhof AJ, et al. Relationship of suicide rates with climate and economic variables in Europe during 2000-2012. Ann Gen Psychiatry (2016) 15:19. doi: 10.1186/ s12991-016-0106-2

30. Burke M, González F, Baylis P, Heft-Neal S, Baysan C, Basu S, et al. Higher temperatures increase suicide rates in the United States and Mexico. Nat Climate Change (2018) 8:723-29. doi: 10.1038/s41558-018-0222-x

31. Dunner DL. Correlates of suicidal behavior and lithium treatment in bipolar disorder. J Clin Psychiatry (2004) 10:5-10.

32. Kim JS, Ha TH, Chang JS, Park YS, Huh I, Kim J, et al. Seasonality and its distinct clinical correlates in bipolar II disorder. Psychiatry Res (2015) 225:540-4. doi: 10.1016/j.psychres.2014.11.051

33. Volpe FM, Tavares A. Del Porto JA. Seasonality of three dimensions of mania: psychosis, aggression and suicidality. J Affect Disord (2008) 108:95-100. doi: 10.1016/j.jad.2007.09.014

34. Mazza M, Di Nicola M, Catalano V, Callea A, Martinotti G, Harnic D, et al. Description and validation of a questionnaire for the detection of meteoropathy and meteorosensitivity: the METEO-Q. Compr Psychiatry (2012) 53:103-6. doi: 10.1016/j.comppsych.2011.02.002

35. First MB, Spitzer RL, Gibbon M, Williams J, Benjamin L. Structured Clinical Interview for DSM-IV Axis II Personality Disorders (SCID-II). Washington, D.C: American Psychiatric Association (1997).

36. First MB, Spitzer RL, Gibbon M, Williams J. Structured Clinical Interview for DSM-IV Axis I Disorders, Research Version, Patient Edition (SCID-I/P, Version 2.0). In: Biometrics Research. New York: New York State Psychiatric Institute (2002).

37. First MB, Spitzer RL, Gibbon M, Williams J. Structured Clinical Interview for DSM-IV-TR Axis I Disorders, Non-patient Edition, (SCID-I/NP). In: Biometrics Research. (New York: New York State Psychiatric Institute) (2002).

38. Silverman MM, Berman AL, Sanddal ND, O'carroll PW, Joiner TE. Rebuilding the tower of Babel: a revised nomenclature for the study of suicide and suicidal behaviors. Part 2: Suicide-related ideations, communications, and behaviors. Suicide Life Threat Behav (2007) 37:26477. doi: 10.1521/suli.2007.37.3.264

39. Hamilton M. A rating scale for depression. J Neurol Neurosurg Psychiatry (1960) 23:56-62. doi: 10.1136/jnnp.23.1.56

40. Young R, Biggs J, Ziegler V, Meyer D. A rating scale for mania: reliability, validity and sensitivity. Br J Psychiatry (1978) 133:429-35. doi: 10.1192/ bjp.133.5.429

41. Geoffroy PA, Lajnef M, Bellivier F, Jamain S, Gard S, Kahn JP, et al. Genetic association study of circadian genes with seasonal pattern in bipolar disorders. Sci Rep (2015) 5:10232. doi: 10.1038/srep 10232

42. Monteleone P, Maj M. The circadian basis of mood disorders: recent developments and treatment implications. Eur Neuropsychopharmacol (2008) 18:701-11. doi: 10.1016/j.euroneuro.2008.06.007

43. Nurnberger Jr. JI, Adkins S, Lahiri DK, Mayeda A, Hu K, Lewy A, et al. Melatonin suppression by light in euthymic bipolar and unipolar patients. Arch Gen Psychiatry (2000) 57:572-9. doi: 10.1001/archpsyc.57.6.572

44. Camardese G, Leone B, Serrani R, Walstra C, Di Nicola M, Della Marca G, et al. Augmentation of light therapy in difficult-to-treat depressed patients: an open-label trial in both unipolar and bipolar patients. Neuropsychiatr Dis Treat (2015) 11:2331-8. doi: 10.2147/NDT.S74861

45. Wehr TA. Bipolar mood cycles and lunar tidal cycles. Mol Psychiatry (2018) 23:923-31. doi: 10.1038/mp.2016.263

46. Di Nicola M, De Risio L, Battaglia C, Camardese G, Tedeschi D, Mazza M, et al. Reduced hedonic capacity in euthymic bipolar subjects: a trait-like feature? J Affect Disord (2013) 147:446-50. doi: 10.1016/j.jad.2012.10.004 
47. Deisenhammer EA. Weather and suicide: the present state of knowledge on the association of meteorological factors with suicidal behaviour. Acta Psychiatr Scand (2003) 108:402-9. doi: 10.1046/j.0001-690X.2003.00209.x

48. McClung CA. How might circadian rhythms control mood? Let me count the ways .... Biol Psychiatry (2013) 74:242-9. doi: 10.1016/j.biopsych.2013.02.019

49. Pompili M, Gonda X, Serafini G, Innamorati M, Sher L, Amore M, et al. Epidemiology of suicide in bipolar disorders: a systematic review of the literature. Bipolar Disord (2013) 15:457-90. doi: 10.1111/bdi.12087

50. Schaffer A, Isometsä ET, Tondo L, Moreno DH, Sinyor M, Kessing LV, et al. Epidemiology, neurobiology and pharmacological interventions related to suicide deaths and suicide attempts in bipolar disorder: Part I of a report of the International Society for Bipolar Disorders Task Force on Suicide in Bipolar Disorder. Aust N Z J Psychiatry (2015) 49:785-802. doi: 10.1177/ 0004867415594427

51. Rudd MD. Suicidality in clinical practice: anxieties and answers. J Clin Psychol (2006) 62:157-59. doi: 10.1002/jclp.20219

52. Makris GD, Reutfors J, Larsson R, Isacsson G, Ösby U, Ekbom A, et al. Serotonergic medication enhances the association between suicide and sunshine. J Affect Disord (2016) 189:276-81. doi: 10.1016/j.jad.2015.09.056

53. Goldberg JF, Singer TM, Garno JL. Suicidality and substance abuse in affective disorders. J Clin Psychiatry (2001) 62 Suppl 25:35-43.

54. Henry C, Phillips M, Leibenluft E, M’Bailara K, Houenou J, Leboyer M. Emotional dysfunction as a marker of bipolar disorders. Front Biosci (2012) 4:2622-30. doi: 10.2741/e578

55. Hofmann SG, Sawyer AT, Fang A, Asnaani A. Emotion dysregulation model of mood and anxiety disorders. Depress Anxiety (2012) 29:409-16. doi: $10.1002 /$ da. 21888

56. Pandey J, Grandner M, Crittenden C, Smith MT, Perlis ML. Meteorologic factors and subjective sleep continuity: a preliminary evaluation. Int $J$ Biometeorol (2005) 49:152-5. doi: 10.1007/s00484-004-0227-1

57. Zheng G, Li K, Wang Y. The Effects of High-Temperature Weather on Human Sleep Quality and Appetite. Int J Environ Res Public Health (2019) 16 (2):E270. doi: 10.3390/ijerph16020270

58. Benard V, Etain B, Vaiva G, Boudebesse C, Yeim S, Benizri C, et al. Sleep and circadian rhythms as possible trait markers of suicide attempt in bipolar disorders: An actigraphy study. J Affect Disord (2019) 244:1-8. doi: 10.1016/ j.jad.2018.09.054

59. Kim CD, Lesage AD, Seguin M, Chawky N, Vanier C, Lipp O, et al. Seasonal differences in psychopathology of male suicide completers. Compr Psychiatry (2004) 45:333-9. doi: 10.1016/j.comppsych.2004.06.007

60. Balestrieri M, Rucci P, Sbrana A, Ravani L, Benvenuti A, Gonnelli C, et al. Lifetime rhythmicity and mania as correlates of suicidal ideation and attempts in mood disorders. Compr Psychiatry (2006) 47:334-41. doi: 10.1016/ j.comppsych.2006.01.004

61. Bauer M, Glenn T, Alda M, Andreassen OA, Angelopoulos E, Ardau R, et al. Association between solar insolation and a history of suicide attempts in bipolar I disorder. J Psychiatr Res (2019) 13:1-9. doi: 10.1016/j.jpsychires.2019.03.001

62. Berardelli I, Corigliano V, Hawkins M, Comparelli A, Erbuto D, Pompili M. Lifestyle Interventions and Prevention of Suicide. Front Psychiatry (2018) 9:567. doi: 10.3389/fpsyt.2018.00567
63. Macrynikola N, Miranda R, Soffer A. Social connectedness, stressful life events, and self-injurious thoughts and behaviors among young adults. Compr Psychiatry (2018) 80:140-9. doi: 10.1016/j.comppsych.2017.09.008

64. Calati R, Ferrari C, Brittner M, Oasi O, Olié E, Carvalho AF, et al. Suicidal thoughts and behaviors and social isolation: A narrative review of the literature. J Affect Disord (2019) 245:653-67. doi: 10.1016/j.jad.2018.11.022

65. Janiri L, Spinetti G, Mazza M, Di Nicola M. Meteoropathy: a new disease. In: Christodoulou GN, Jeorge M, Mezzich JE, editors. Advances in Psychiatry, vol. 3. (Athens: Beta Medical Publishers) (2009). p. 45-52.

66. Berry HL, Bowen K, Kjellstrom T. Climate change and mental health: a causal pathways framework. Int J Public Health (2010) 55:123-32. doi: 10.1007/ s00038-009-0112-0

67. Burke SEL, Sanson AV, Van Hoorn J. The Psychological Effects of Climate Change on Children. Curr Psychiatry Rep (2018) 20:35. doi: 10.1007/s11920-018-0896-9

68. Coverdale J, Balon R, Beresin EV, Brenner AM, Guerrero APS, Louie AK, et al. Climate change: a call to action for the psychiatric profession. Acad Psychiatry (2018) 42:317-23. doi: 10.1007/s40596-018-0885-7

69. Kirch DG, Petelle K. Addressing the health effects of climate change: an approach based on evidence and ethics. Acad Psychiatry (2018) 42:324-6. doi: $10.1007 /$ s40596-018-0907-5

70. Obradovich N, Migliorini R, Paulus MP, Rahwan I. Empirical evidence of mental health risks posed by climate change. Proc Natl Acad Sci U S A (2018) 115:10953-58. doi: 10.1073/pnas.1801528115

71. Stewart AJ. Psychiatry's role in responding to climate change. Acad Psychiatry (2018) 42:327-8. doi: 10.1007/s40596-018-0909-3

72. Van Susteren L. The psychological impacts of the climate crisis: a call to action. BJPsych Int (2018) 15:25-6. doi: 10.1192/bji.2017.40

73. Ursano R, Morganstein J, Cooper R. American Psychiatric Association Position Statement: Mental Health and Climate Change. www.psychiatry. org. Accessed 02/08/2019. doi: 10.13140/RG.2.2.26846.64325

74. Arango C. (2018). Climate change and Brain Health. Available online at https:// www.ecnp.eu/Informationandnews/presidents_blog/August\%202018.aspx.

75. Bourque F, Willox AC. Climate change: the next challenge for public mental health? Int Rev Psychiatry (2014) 26:415-22. doi: 10.3109/09540261.2014.925851

76. Stone DM, Simon TR, Fowler KA, Kegler SR, Yuan K, Holland KM, et al. Vital Signs: Trends in State Suicide Rates - United States, 1999-2016 and Circumstances Contributing to Suicide - 27 States, 2015. MMWR Morb Mortal Wkly Rep (2018) 67:617-24. doi: 10.15585/mmwr.mm6722al

Conflict of Interest: The authors declare that the research was conducted in the absence of any commercial or financial relationships that could be construed as a potential conflict of interest.

Copyright (c) 2020 Di Nicola, Mazza, Panaccione, Moccia, Giuseppin, Marano, Grandinetti, Camardese, De Berardis, Pompili and Janiri. This is an open-access article distributed under the terms of the Creative Commons Attribution License (CC BY). The use, distribution or reproduction in other forums is permitted, provided the original author(s) and the copyright owner(s) are credited and that the original publication in this journal is cited, in accordance with accepted academic practice. No use, distribution or reproduction is permitted which does not comply with these terms. 